\title{
SCIENCE VERSUS SCIENCE EDUCATION
}

\section{Iwona Maciejowska}

Jagiellonian University, Poland

Scientific process consists in multiple repetitions of researches in order to verify their results. They are also publicized and undergo the process of criticism and evaluation by the scientific community. The science is the social process in which the scientists constantly look at the results of the others' work, accept them or reject based on the objective criteria. It happens through the review of the text intended for publication as well as publication of polemical and critical texts. Also during the scientific conferences there is a time for discussions among scientists, which influence the direction of the development of a field of knowledge and of the researches. This process was clearly visible during the last few conferences on chemistry and sciences education. During the $22^{\text {nd }}$ ICCE and $11^{\text {th }}$ ECRICE in Rome Prof. Mansoor Niaz noted that in thicker and thicker, 1000-page, containing more and more knowledge textbooks there should be a place (e.g. additional 100 pages) for history of the chemical concepts, including doubts accompanying development of science, illustrating the thesis that it was a very complicated process, not linear at all. In response, Prof. Peter Atkins said that the textbooks did not contain more and more concepts and new knowledge but rather more and more „help“ for students - more examples, exercises, visualizations - models, diagrams, charts which are crucial especially for those, in case of whom English is not the first language. According to him, adding $10 \%$ of additional factual knowledge is pointless.

During the same conference Prof. Alexander Renkl proved that the students who participate in lessons the most actively do not achieve better results than passive students (listeners) and adding the context to the task makes it more difficult to resolve. In response to that, a person from the audience asked about the preparation of the pupils and university students to requirements of the contemporary world in which the graduates have to face not easy, clearly defined questions but complex problems which always occur in some context.

Also on the $2^{\text {nd }}$ International Scientific Seminar Science-Society-Didactics in Cracow, participants had opportunities to listen to the lecture on constructivism-based IBSE strategy illustrated with an example of 7PR ESTABLISH project, and to the lecture of Prof. Andre Giordan in which the significant limitations of constructivism were expressed in words: ,a student sees and hears what he/she expects to“, „he/she comprehends from the angle of what he already knows", „from the conception which he can mobilize.“

It is interesting to listen to the discussion between authorities and as a result to be able to develop one's own opinion. Using IBSE strategy we refer to these rules of the scientific method - necessity of critical analysis and discussion on the results. That is what we also expect from our students - to be critical to the information, especially to the popular one, provided by mass media, to statements of their colleagues and to the results of their researches, to be able to express their own points of view and formulate conclusions on the basis of reliable assumptions. It is not an easy task, but it is worth trying. Deluge of information of various quality - the phenomena characteristic for the contem- 
porary civilization, results in challenges different to those that had to be faced 50 years ago. Prof. Vincenzo Balzani said in Rome: „Today scientists know almost everything about almost nothing, whereas in the past they knew almost anything about almost everything".*

*all quotations come from the author's notes, they were not authorized

Received 27 July 2012; accepted 25 August 2012

\section{Iwona Maciejowska}

$\mathrm{PhD}$, Vice Chair DivCEd EuCheMS, Faculty of Chemistry, Jagiellonian University, 3 Ingardena, 30060 Krakow, Poland

E-mail: maciejow@chemia.uj.edu.pl

Website: http://www.chemia.uj.edu.pl/maciejow/ 